ENCYCLOPÉDIE Encyclopédie berbère

BERBERE

28-29 | 2008

28-29 | Kirtēsii - Lutte

\title{
Lembetet el-Kbir
}

N. Lambert

\section{OpenEdition}

Journals

Édition électronique

URL : http://journals.openedition.org/encyclopedieberbere/322

DOI : $10.4000 /$ encyclopedieberbere.322

ISSN : 2262-7197

\section{Éditeur}

Peeters Publishers

\section{Édition imprimée}

Date de publication : 1 janvier 2008

Pagination : 4364

ISBN : 2-7449-0707-4

ISSN : 1015-7344

\section{Référence électronique}

N. Lambert, «Lembetet el-Kbir », Encyclopédie berbère [En ligne], 28-29 | 2008, document L12, mis en ligne le 01 juin 2013, consulté le 24 septembre 2020. URL : http://journals.openedition.org/ encyclopedieberbere/322 ; DOI : https://doi.org/10.4000/encyclopedieberbere.322

Ce document a été généré automatiquement le 24 septembre 2020

(c) Tous droits réservés 


\section{Lembetet el-Kbir}

\section{N. Lambert}

1 Nécropole située en Mauritanie* occidentale à un kilomètre au nord du Guelb Moghrein (carte des régions sahariennes au $2000000^{\mathrm{e}}$, feuille Akjoujt NE 28XXIII c.l. 19e $45^{\prime} \mathrm{N}-14^{\circ}$ $\left.26^{\prime} \mathrm{W}\right)$. Elle comprend 160 tombeaux répartis sur tout le petit massif de quartzite. Lembetet el-Kbir s'élève d'une quarantaine de mètres au-dessus du reg alentour et, vers le nord, domine la vallée et le barrage du Khat Lekheijat. Le site a été découvert en 1958.

2 Les tombes sont de trois sortes : tumulus, bazinas* à trois degrés et deux barkhanes ou monuments en croissants. Ces deux derniers types ont été édifiés sur le sommet et à la partie supérieure des pentes, les tumulus occupent le reste de l'affleurement rocheux jusqu'à la plaine.

3 En surface on a recueilli des fragments de meules dormantes et molettes en roche verte, des armatures de flèches, grattoirs et pointes en silex, quelques tessons de céramique sans décor.

4 Les fouilles (en 1959 et en 1968) ont permis l'étude de 7 monuments (5 bazinas, 1 tumulus, et la grande barkhane).

5 Les tombes à degrés ou bazinas sont circulaires, constituées par trois assises concentriques. La chambre funéraire, au centre, est construite en encorbellement et a parfois un plancher de dalles sur lequel a été déposé le corps. La taille de ces monuments varie peu: pour $7 \mathrm{~m}$ de diamètre extérieur et $1,10 \mathrm{~m}$ de hauteur, la chambre centrale mesure $1,20 \mathrm{~m}$ de diamètre et 0,75 à $0,80 \mathrm{~m}$ de hauteur. Un sable très fin et compact comble cette cavité. Le mobilier à l'intérieur de ses tombes est inexistant mais quelques restes humains y ont été recueillis.

6 La grande barkhane appartient à un type de monuments bien connu mais rarement fouillé. L'énorme amas de pierre (parmi lesquels on note la présence de meules dormantes et de molettes brisées) prend la forme d'une barkhane de sable : la pente intérieure du croissant est nettement plus abrupte que la pente extérieure. L'amas de pierres ainsi constitué mesure $27,60 \mathrm{~m}$ à l'ouverture des branches, sa puissance au centre est de $14 \mathrm{~m}$ et sa hauteur est de $2 \mathrm{~m}$. Le croissant est ouvert vers l'est. La fouille a mis au jour une structure circulaire de $3 \mathrm{~m}$ de diamètre et de $0,60 \mathrm{~m}$ de hauteur, 
composée de blocs de quartzite mal appareillés. Ce cercle, qui se trouve au centre de la barkhane et au niveau du sol du plateau, était absolument vide.

7 C'est la proximité immédiate du Guelb Moghrein et de la Grotte aux chauves-souris qui a attiré l'attention sur cette nécropole de Lembetet el-Kbir, seul groupe de tombes de quelque importance dans les environs immédiats de l'exploitation antique de cuivre d' Akjoujt* (EB III, p. 417-419).

\section{BIBLIOGRAPHIE}

LAMBERT N., 1965. « Nomenclature et première étude de quelques sites préhistoriques de la région d'Akjoujt », BIFAN, t. XXVII, série B, n³-4, 1965, p. 800-812, fig. 8.

LAMBERT N., 1969. « Exploitation minière et métallurgique protohistorique du cuivre au Sahara occidental », communication à l'Assemblée conjointe de l'ASA et du Conseil Canadien d'Études africaine, Montréal 1969.

INDEX

Mots-clés : Funéraire, Préhistoire, Protohistoire, Sahara 